\title{
Sábato por Edla
}

[Sábato by Edla

\section{Edla van Steen ${ }^{\mathrm{x}}$}

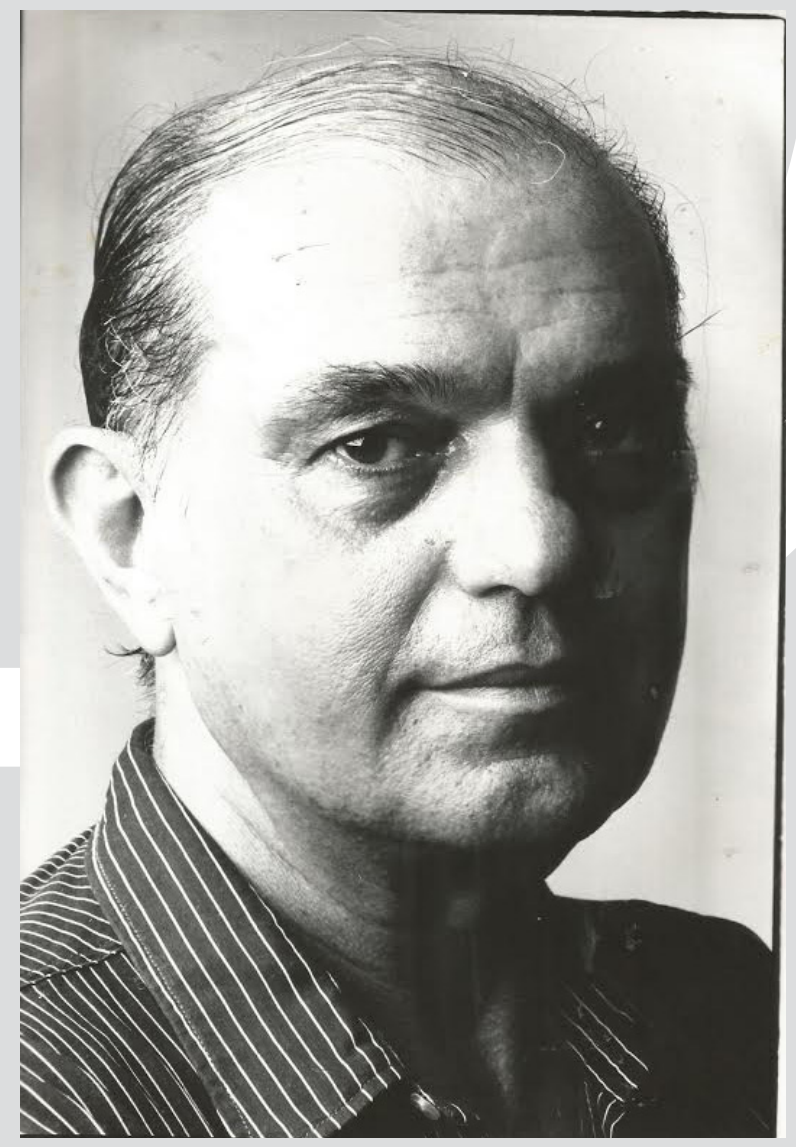

VAN STEEN, Edla. Sábato por Edla. Revista do Instituto de Estudos Brasileiros, Brasil, n. 68, p. 259-265, dez. 2017.

DOI: http://dx.doi.org/Io.II6o6/issn.23I6-90IX.voi68p259-265

I Escritora. 
RIEB - Que lembranças Sábato Magaldi compartilhava do contato com Mário de Andrade em Belo Horizonte, em I944, quando tinha I7 anos? E quais memórias perduraram do grupo de jovens intelectuais mineiros com o qual convivia nesse momento?

Edla van Steen - Sábato era primo de Hélio Pellegrino, psicanalista e poeta, mais velho do que ele e amigo de Fernando Sabino, Otto Lara Resende e Paulo Mendes Campos, todos convidados a participar da revista $O$ Edifício, fundada e dirigida pelo grupo mais jovem, formado pelo jornalista e poeta Wilson Figueiredo, o historiador Francisco Iglésias, o poeta e romancista Octávio Mello Alvarenga, Jacques do Prado Brandão, entre outros, e pelo Sábato, que ainda não pensava em teatro, era crítico literário. A visita do Mário de Andrade foi um acontecimento para os dois grupos. Generoso, Mário de Andrade passou a se corresponder com vários deles, reconhecendo-lhes os talentos.

Recém-formado em Direito, Sábato mudou-se para o Rio de janeiro aos 2I anos para trabalhar em sua área do conhecimento. Como se deu sua entrada no jornalismo e, especificamente, como se tornou crítico teatral?

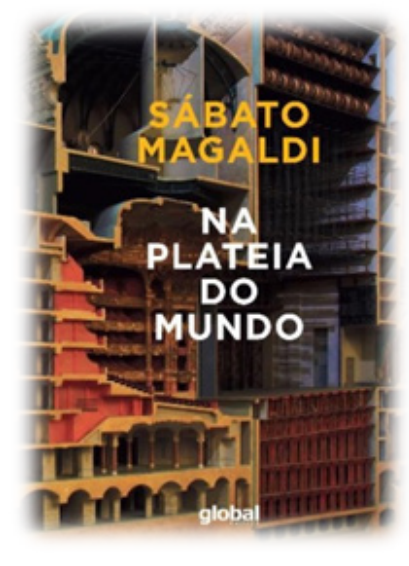

Sábato sempre leu muito. Seus primeiros artigos foram publicados em Belo Horizonte; Cyro dos Anjos precisava de um chefe de gabinete e convidou Sábato, o advogado, recém-formado, que gostava de escrever. Paulo Mendes Campos trabalhava no Diário Carioca, e não gostava de ir ao teatro. A coluna foi oferecida ao Sábato, que aceitou. É impressionante como as primeiras críticas eram boas. Sábato dividia a apreciação em três ou quatro comentários. Um sobre o texto e o autor, outro sobre a direção, mais um sobre a interpretação, e ainda analisava os figurinos, a iluminação etc. Não sei como era possível, numa época sem internet!!! Em Na plateia do mundo² foram publicadas as críticas de espetáculos

2 MAGALDI, Sábato. Na plateia do mundo. Pesquisa, seleção e organização: Edla van Steen. São Paulo: Global, 2017. 
estrangeiros que iam ao Rio de Janeiro, principalmente franceses e italianos. Os cariocas lotavam as salas. Foi então que ele sentiu que precisava estudar. Candidatou-se a uma bolsa, e se mudou para Paris. Fez o curso de Estética. E continuou a coluna, enviando críticas dos espetáculos estrangeiros. Impressionante a crítica que ele enviou da estreia teatral de Ionesco.

Afirmar que se trata de tentativa nova em teatro seria muito e seria pouco. Muito, porque experiências semelhantes no terreno da linguagem já foram tentadas, e pouco, porque o resultado é mais do que simples experiência - é uma realização, uma obra definida, importante. Muito importante, a meu ver3 [sobre A cantora careca].

Qual foi a importância, para Sábato, dos estudos que desenvolveu na Sorbonne, em Paris, no início dos anos I950?

O curso de Étienne Souriau, autor do livro As duzentas mil situações dramáticas, foi importantíssimo. E, principalmente, ter visto muito teatro.

Sabemos que Sábato, ao voltar para o Brasil, aceitou o convite de Alfredo Mesquita para ser professor de História do Teatro na Escola de Arte Dramática -EAD e transferiu-se para São Paulo, onde também atuou como titular da coluna de teatro do Suplemento Literário d'O Estado de S. Paulo. A seu ver, qual a contribuição de Sábato para a modernização do teatro brasileiro então em curso?

Acho que o amor dele pelo teatro brasileiro como um todo foi o mais importante. Sábato sempre lia os textos, apontava defeitos - Jorge Andrade refez uma peça não sei quantas vezes -, e ele, atenciosamente, lia de novo as mudanças, argumentava e o convencia a melhorar suas peças. Fez isso com muitos autores. Além disso, ele participava de seminários de dramaturgia, prefaciava edições de livros, dirigia coleções teatrais, tanto na Editora Brasiliense, como na Abril, participava de assembleias. Sempre foi cúmplice do teatro. E defendeu a participação do Estado no teatro, na produção de espetáculos. Abominava a Censura, que nunca deixou em paz o nosso teatro.

Além de crítico teatral, Sábato foi professor de História do Teatro Brasileiro na Escola de Comunicações e Artes - ECA. Desenvolveu a tese de doutorado sobre o teatro de Oswald de Andrade e a livre-docência sobre Nelson Rodrigues. Escreveu muitos ensaios e formou mestres e doutores na pós-graduação. Como você avalia a contribuição de Sábato para a pesquisa sobre o teatro no Brasil?

O que posso dizer é que ninguém no Brasil publicou tantos livros da área quanto ele. Afinal são 20 títulos. Além de ter deixado uma biblioteca fantástica, doada por mim para a Universidade Federal de Minas Gerais - UFMG, que ajudará os pesquisadores. Quando ele se aposentou da Universidade, tinha I4 orientandos, e a nossa casa era um porto seguro para resolverem suas dúvidas e receberem orientação. Acho que os

3 Idem. La cantatrice chauve e La leçon. (I953). In: . Na plateia do mundo. São Paulo: Global, 2017. 
livros dele, como $O$ texto no teatro ${ }^{4}$, Panorama do teatro brasileiro ${ }^{5}$ e Depois do espetáculo ${ }^{6}$, para citar apenas alguns, são contribuições valiosas.

Vocês se casaram em 1978. Como foi acompanhar, você e Sábato, a abertura política e suas reverberações no teatro brasileiro?

Na verdade, ele se mudou para a minha casa em julho de I979, quando nossa relação foi oficializada. A situação já estava melhor, mas as dívidas dele eram imensas. Sábato pagava todas as despesas de compras de livros, almoços e jantares com pessoas de teatro, diretores e atores de peças estrangeiras que vinham ao Brasil, não tinha nem pedia ajuda de custo para nada. Conclusão: ao deixar a Secretaria Municipal de Cultura de São Paulo, ele tinha uma dívida de cartão que levou dois anos pagando. Em I977, o Teatro Ruth Escobar promoveu o Seminário de Dramaturgia Brasileira, que foi chamado de "O festival do proibido", às segundas-feiras, durante três meses. Leitura dramática de doze textos, de autoria de Augusto Boal (Mulheres de Atenas), Oduvaldo Vianna Filho (Rasga coração), Nelson Xavier (Trivial simples), Antônio Bivar (A passagem da rainha), Plínio Marcos (Barrela), Chico Buarque de Holanda e Ruy Guerra (Calabar, o elogio da traição), Consuelo de Castro (A cidade impossível de Pedro Santana), Renata Pallottini (Enquanto se vai morrer), Gianfrancesco Guarnieri (Basta!), Carlos Queiroz Telles (A heroica pancada), Lauro César Muniz (Sinal de vida) e Jorge Andrade (Milagre na cela). Como a censura ainda fosse muito severa, as circunstâncias não permitiram a encenação de nenhum dos textos, embora entre eles figurassem alguns dos mais representativos da nossa dramaturgia. Ele dizia que fazer teatro, durante a ditadura, era prova de heroísmo. O palco se tornou imperativo de vocação irrecusável, que se afirmava contra tudo e contra todos. A Censura chegou ao sadismo de proibir a montagem no dia da estreia, exultando em levar à falência o empresário do espetáculo. Assim, de repente, lembro de um ensaio escrito pelo Sábato em I987, publicado pela Fundação Calouste Gulbenkian: "O texto no moderno teatro brasileiro"?. Um primor pela concisão e revelação da nossa dramaturgia.

Como se deu o ingresso de Sábato na Academia Brasileira de Letras? Que trabalhos ele desenvolveu como acadêmico?

Lêdo Ivo e Antonio Houaiss insistiram que ele se candidatasse. O teatro brasileiro merecia um representante e tal e coisa. Ele teve 35 votos. E muitos atores e diretores de teatro compareceram à posse. Pouca gente sabe que a Academia dá prêmios no total de 500 mil reais por ano. Que promove todas as terças-feiras conferências literárias com quase 500 pessoas na plateia. Que, em momentos econômicos melhores do Brasil, a ABL editava livros, não só de e sobre acadêmicos. Pensa-se mal da Academia por falta de conhecimento. É uma entidade literária da maior importância.

\footnotetext{
4 Idem. O texto no teatro. 3. ed. São Paulo: Perspectiva, 20I2. (Coleção Estudos).

5 Idem. Panorama do teatro brasileiro. I. ed. São Paulo: Difusão Europeia do Livro, I962.

6 Idem. Depois do espetáculo. São Paulo: Perspectiva, 2003.

7 Idem. O texto no moderno teatro brasileiro. Arquivos do Centro Cultural Português, v. 23. Lisboa-Paris: Fundação Calouste Gulbenkian, I987.
} 
Como se dava a sociabilidade de Sábato com autores teatrais e atores?

Ele era uma pessoa alegre, adorava ter amigos em casa. E eu não ficava atrás. Principalmente porque eu gosto de cozinhar. E Sábato não se intimidava de escrever exatamente o que pensava dos espetáculos. Tônia Carrero, Paulo Autran, Walmor Chagas, Eva Wilma, Augusto Boal, Italo Rossi, Irene Ravache, Maria Adelaide Amaral, Juca de Oliveira, Ney Latorraca, para citar só alguns, diretores, dramaturgos, amigos sempre presentes nos nossos jantares, por causa da amizade que nos unia, confiavam no critério crítico. Os papos teatrais são deliciosos. A classe é muito engraçada, crítica e inteligente.

\section{Como trabalhava Sábato em sua atividade de crítico?}

Ao sair de um espetáculo, fora dizer se tinha gostado ou não, anotava nos diários dele os detalhes que ele ia desenvolver no dia seguinte, ao escrever a crítica. Escrevia sempre com caneta Bic. Eu nunca li os diários - ele intitulou de Crônica Teatral. Vi que alguns cadernos têm folhas arrancadas, e que faltam alguns, todos com data anterior ao nosso casamento. Serão doados à Academia Brasileira de Letras - ABL. Sábato pediu que só fossem consultados 30 anos depois da sua morte. Acho que são 48 ou 49 cadernos de 400 páginas.

\section{Sábato ensaiou, em algum momento, a dramaturgia?}

Que eu saiba, nunca. Como eu disse, quando jovem ele queria ser crítico literário. Talvez tivesse escrito alguns poemas. O Octávio Alvarenga falava neles. Não encontrei nenhum.

Como Sábato organizava o seu arquivo? Correspondia-se com amigos intelectuais? Quem era o seu principal correspondente?

Sábato não tinha arquivo. Ele empilhava papéis, jornais, correspondências, originais de críticas, roteiros para as aulas, que ele sempre preparava no dia anterior (ele se gabava de nunca ter repetido uma aula) e que acabava depois perdida no meio da papelada. Quando nós saímos do Morumbi, tentei separar tudo em caixas que ele jamais consultou. A verdade é que ele, além da atividade como jornalista, era procurador do INSS, professor na USP, e secretário de Cultura do Município de São Paulo, durante cinco anos. Trabalhou demais a vida toda. Não tinha tempo para nada. A biblioteca, um caos. Reconheço que desenvolvi rapidamente um viés de bibliotecária para dar um jeito no nosso apartamento. Ele nunca foi de escrever cartas para os amigos. No máximo respondia com pequenos bilhetes. Francisco Iglésias escrevia muito para nós quando estávamos morando na França. Fazia enormes relatórios do que acontecia aqui. Mas Sábato jamais guardou as cartas em pastas ou coisa parecida. O que se salvou da bagunça total está na UFMG.

Como era acompanhar Sábato nas apresentações teatrais? Como ele formulava as suas primeiras percepções críticas?

Ele detestava ir a estreias e a segundas récitas. Preferia ver espetáculos quando já estivessem prontos, com a luz perfeita. Se alguém do elenco perguntasse cara a cara o que ele tinha achado, ele falava claramente. Eu ficava aflita e me afastava. Mas, 
em geral, nós saíamos rapidamente do teatro, para evitar constrangimentos. Comigo ele evitava exclamações. Eu deixava para saber a opinião dele lendo-a na publicação.

\section{Sábado e Edla, em que momentos trabalharam a quatro mãos?}

Copidescávamos os textos um do outro. E eu digitava alguns dele, já que Sábato não chegou a usar máquina elétrica. Preferia a Erica antiga, ou a minha Olivetti, e rabiscava em cima. Hábitos de jornalista. Em geral, Sábato era bastante calmo, muito educado, mas virava um bicho malcriado quando algum linotipista do jornal errava grafia de nomes ou comia uma ou algumas linhas das críticas. Aí a descompostura brotava firme, em alto e bom som. Aliás, ele não pensou em publicá-las em livro. Eu insisti algumas vezes, ele dizia "só se você fizer o trabalho".

Sábato participava do processo de criação literária de Edla? Como era Sábato leitor e crítico de Edla?

Como ele era ocupadíssimo, lia meus livros quando já estavam na prova, e dava sugestões em palavras repetidas, ou nas vírgulas. Não vou ser modesta. Ele sempre gostou da minha ficção, dos meus livros Viver e escrever, entrevistas com 39 autores - do meu trabalho na Global, dirigindo várias coleções. A literatura nos uniu.

Como foi a organização dos últimos dois livros de Sábato, reunindo suas críticas teatrais em Amor ao teatro 8 Na plateia do mundo. $O$ primeiro livro tem impressionantes $\mathrm{I} .223$ páginas e o segundo, 47I. O que motivou você a fazer esses livros e como os concebeu?

Fiz o Amor ao teatro enquanto ele estava vivo. Eu consegui que ele participasse, pois, apesar de já estar doente, tinha momentos de lucidez e me ajudou bastante na eliminação de críticas. O Vendramini também me deu uma força, concordando com a seleção. Nós dois decidimos deixar o teatro estrangeiro para um outro volume.

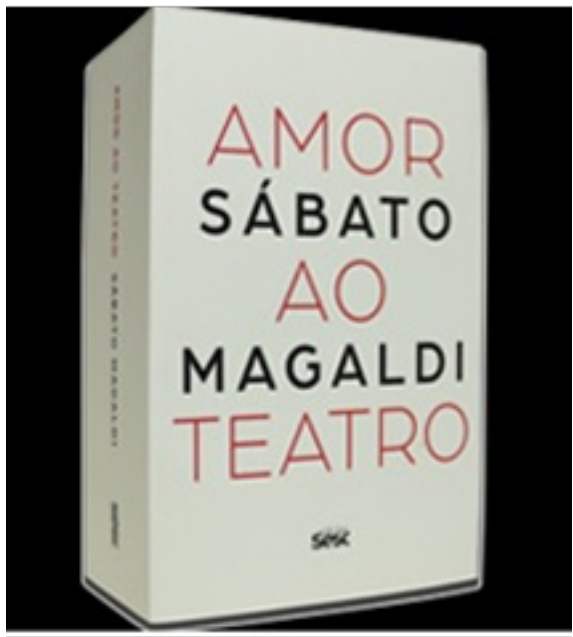
Sábato ficou muito feliz quando viu o livro pronto. Ele não queria que fosse dividido em dois ou três volumes, como tínhamos inicialmente pensado. Mas não tenho certeza se ele havia imaginado o tamanho do trabalho. Quem foi ao lançamento no Serviço Social do Comércio - Sesc, viu a felicidade com que ele dava os autógrafos.

$\mathrm{Na}$ plateia do mundo estava com a pesquisa bem adiantada. O mais complicado foi encontrar os anos I950 do Diário Carioca e digitar os textos de difícil leitura. É surpreendente como Sábato estava pronto como crítico aos 22 anos. A seriedade com que analisava o teatro, a isenção, a clareza com que informava o público e os

8 Idem. Amor ao teatro. São Paulo: Edições Sesc, 2015. 
envolvidos nos espetáculos, durante 38 anos, precisavam ser reunidas nesses dois volumes. Aproveito aqui para reproduzir um pequeno trecho de um artigo:

O futuro do teatro, como sempre, liga-se a preocupações de natureza estética e econômica. No campo da economia, o Estado, mais do que nunca, precisa assumir sua inteira responsabilidade, evitando os mecanismos burocratizantes, não interferindo na liberdade de expressão. Quanto ao aspecto estético, toda vez que os caminhos se mostram nebulosos, vale a pena recorrer à origem do fenômeno cênico e à razão de sua essência. Homens dialogando entre si e com o público, os atores são o instrumento vivo de uma arte que, fundada na palavra e na expressão corporal, sob o comando do encenador, renova a cada espetáculo o mistério da criação.

O teatro foi a grande paixão de Sábato Magaldi.

\section{SOBRE A AUTORA}

EDLA VAN STEEN é autora de trinta livros publicados, entre contos, romances, entrevistas, peças de teatro, livros de arte. Prêmios Molière e Mambembe categoria Melhor autor, de teatro, pela peça $O$ último encontro. Prêmio Coelho Neto da Academia Brasileira de Letras e Prêmio Nacional do Pen Club (Madrugada, romance ). Prêmio Nestlé de Literatura Brasileira, categoria Autor consagrado (Cheiro de amor, contos). Teve publicados nos Estados Unidos os livros: A bag of stories, Village of the ghost bells, Early mourning e Scent of love, todos traduzidos por David S. George. Dirige várias coleções literárias na Global Editora, desde I980. Medalha Cruz e Souza em 20I7, pelo trabalho nas letras brasileiras.

\section{REFERÊNCIAS BIBLIOGRÁFICAS}

MAGALDI, Sábato. Panorama do teatro brasileiro. I. ed. São Paulo: Difusão Europeia do Livro, I962. . O texto no moderno teatro brasileiro. Arquivos do Centro Cultural Português, v. 23. Lisboa-Paris:

Fundação Calouste Gulbenkian, I987.

. Depois do espetáculo. São Paulo: Perspectiva, 2003. . O texto no teatro. 3. ed. São Paulo: Perspectiva, 20I2. (Coleção Estudos). . Amor ao teatro. São Paulo: Edições Sesc, 2015. . Na plateia do mundo. Pesquisa, seleção e organização: Edla van Steen. São Paulo: Global, $20 I 7$. 